\title{
Relaxation of Prestressing Steel at Varying Strain and Temperature: Viscoplastic Constitutive Relation
}

\author{
Zdeněk P. Bažant, Hon.M.ASCE ${ }^{1}$; and Qiang $\mathrm{Yu}^{2}$
}

\begin{abstract}
Recent studies of excessive multidecade deflections of prestressed segmentally erected box girders revealed that more accurate predictions of the prestress loss due to steel relaxation are needed for the design of large-span creep-sensitive structures. In particular, the loss needs to be calculated as part of creep structural analysis, during which the strain of concrete to which the prestressing steel is bonded varies in each time step. The existing empirical formulas used in the European Model Code and American practice, which are valid only for constant strain and constant temperature, are here generalized to arbitrarily variable strain and temperature, heeding obvious asymptotic restrictions and the fact that steel is a viscoplastic material whose constitutive principles are well known. The resulting formula is a memoryless nonlinear equation for the viscoplastic strain rate of steel as a function of the current stress, strain, and temperature. Close fits of all the main test data from the literature, including the available data on the effects of strain and temperature changes, are achieved. The effect of temperature is found to be quite important and is formulated on the basis of the activation energy of viscoplastic flow of metals. Finally, the need for further tests at variable strain and variable temperature is emphasized. DOI: 10.1061/(ASCE)EM.1943-7889.0000533. @ 2013 American Society of Civil Engineers.
\end{abstract}

CE Database subject headings: Prestressing; Relaxation (mechanical); Viscoplasticity; Steel; Temperature effects.

Author keywords: Prestress loss; Relaxation; Viscoplasticity.

\section{Introduction}

The stress relaxation of prestressing steel tendons is normally measured at constant strain and constant temperature. The measurement results, embodied in simple formulas, are then used directly in the calculation of prestress losses. This classical approach is contingent on assuming the strain changes during structural lifetime to be negligible compared with the initial strain in steel and the temperature changes to be unimportant. Recently, however, it transpired that in creep-sensitive structures such as large-span segmentally erected box girders, the strain changes in concrete are not negligible, and the temperature rise in concrete slabs exposed to sun may be important.

The importance of strain changes in steel was brought to light by the 2008 unsealing of previously sealed data from the investigation of the 1996 collapse of the Koror-Babeldaob (KB) Bridge in Palau. Built in 1977, with a world-record span of $241 \mathrm{~m}$ (791 ft), this prestressed segmentally erected box girder suffered grossly excessive creep deflections that, within 18 years, reached $1.61 \mathrm{~m}$ (compared with the design camber). In 1996, a retrofit with installation of additional external tendons inside the box was undertaken to lift the bridge, and the bridge was then reopened to traffic. Three months later, the bridge suddenly collapsed (with fatalities) probably due to

\footnotetext{
${ }^{1}$ McCormick Institute Professor and W. P. Murphy Professor of Civil Engineering and Materials Science, Dept. of Civil Engineering and Mechanical, Northwestern Univ., Evanston, IL 60208 (corresponding author). E-mail: z-bazant@northwestern.edu

${ }^{2}$ Assistant Professor, Univ. of Pittsburgh, Pittsburgh, PA 15261; formerly, Assistant Research Professor, Dept. of Civil Engineering and Materials Sciences, Northwestern Univ., Evanston, IL 60208.

Note. This manuscript was submitted on October 20, 2011; approved on August 21, 2012; published online on August 30, 2012. Discussion period open until December 1, 2013; separate discussions must be submitted for individual papers. This paper is part of the Journal of Engineering Mechanics, Vol. 139, No. 7, July 1, 2013. (CASCE, ISSN 0733-9399/ 2013/7-814-823/\$25.00.
}

creep-delamination buckling of the top slab. After the resulting litigation was complete, all the data were sealed in perpetuity, but thanks to a resolution of the Structural Engineers World Congress in November 1997 [introduced by Bažant; see Bažant et al. (2010)], the technical data were released 2 months later to Northwestern University, and their scientific analysis could begin.

As a unique aspect of the investigation in 1996, just before installing the additional external tendons, three of the original tendons were sacrificed to determine their prestress loss by stress-relief tests. At three different locations on each of three tendons, the concrete cover was removed, tendons were bared, and strain gauges were glued to the prestressing steel. The tendons were then cut, and their stress was back-calculated from the shortening measured by the gauges. The result was startling - the average prestress loss was $50 \%$, whereas in design the standard estimate of $22 \%$ was used.

A three-dimensional (3D) creep analysis (Bažant et al. 2010), which succeeded in explaining the excessive deflections, highlighted the importance of using a realistic concrete creep model. Subsequent refined analysis (Bažant et al. 2012a, b) further showed that the use of a good model of steel relaxation at variable strain and temperature is, in the case of large-span creep-sensitive structures, imperative.

Calculations showed that the tendon temperature in the top slab must have reached about $40^{\circ} \mathrm{C}$ each afternoon. They also showed that the strain in the top-slab tendons of the KB Bridge must have decreased by about $30 \%$ over 18 years. It might seem surprising that the excessive deflection did not produce a strain increase with major cracking in the top slab. This would, of course, be the case if the deflection were caused purely by flexure under overload. The creep and shrinkage, however, cause not only flexure but also significant shortening of the girder, which explains why the tendon strain decreased.

Further efforts led to the acquisition of sufficient data for five other excessively deflecting box girders in Japan and the Czech Republic. The same kind of detailed analysis resulted in similar conclusions (Bažant et al. 2012a, b). 
A subsequent search under the auspices of a newly formed RILEM Committee TC-MDC (Multi-Decade Creep) revealed similar histories of excessive or nearly excessive deflections of 69 prestressed segmental box girders in 11 countries (Bažant et al. 2011a, b, c). It is estimated that hundreds of excessively deflecting bridges of this kind exist worldwide. Although it has not been possible to obtain sufficient data for 3D FEM analysis of these bridges, it could nevertheless be concluded that the tendons in these bridges must have undergone similar significant strain and temperature changes.

To check whether excessive deflections might develop and to find a good design that avoids such deflections, a realistic constitutive model for steel relaxation is one requisite tool. To develop such a model is the goal of this paper.

It should be emphasized that the excessive deflections caused by concrete creep and steel relaxation cannot cause structural failure by themselves. They only result in an abrupt change in roadway slope, increased vibrations, traffic speed limitations, water runoff problems, possibly also excessive cracking allowing enhanced ingress of corrosive agents, higher maintenance costs, and ultimately, bridge closing. The retrofit that may be provoked by excessive deflections is sometimes risky and can cause unexpected failure (as exemplified by the KB Bridge in Palau).

It should further be noted that accurate estimation of prestress loss is important for structures dominated by self-weight. This is the case for large spans, roughly over $80 \mathrm{~m}$. For small spans, for which the selfweight is a relatively small fraction of the total maximum load, the errors of the classical simple estimates of prestress loss do not matter.

\section{Design Codes: Fédération Internationale de Béton Formula for Constant Strain and Temperature}

While the American Concrete Institute (ACI) Standard 318-05 (Section 18.6) and Commentary (ACI 2005a, b) specify no particular formula for the prestress loss caused by steel relaxation, the Comité Euro-International du Béton (CEB) Model Code 1990 (CEB 1990), later co-opted by the Fédération Internationale de Béton (fib 2010), does. Its formula is

$$
\frac{\sigma_{0}-\sigma(t)}{\sigma_{0}}=\rho_{1}\left(\frac{t}{\lambda_{1}}\right)^{k} \quad \text { for } \epsilon=\text { constant }
$$

where $t=$ time elapsed since the transfer of prestress force onto concrete, $\sigma=$ axial (normal) stress in the steel bar or wire, $\sigma_{0}=$ initial prestress $=$ stress in tendon when the prestressing force is transferred to the anchor (which is usually also the maximum stress ever experienced by the tendon), $\sigma_{0}-\sigma(t)=$ prestress loss at time $t$, and $\lambda_{1}=1,000 \mathrm{~h}$. Parameter $\rho_{1}$ has different values for three classes of prestressing steel: normal wires and strands (Class 1), improved wires and strands (Class 2), and bars (Class 3), for which, respectively, $\rho_{1}=8 \%, 2 \%$, and $4 \%$ if $\sigma_{0} / f_{p}=0.7 ; 4 \%, 1 \%$, and $2 \%$ if $\sigma_{0} / f_{p}=$ 0.6 ; and $12 \%, 5 \%$, and $7 \%$ if $\sigma_{0} / f_{p}=0.8$ (later it will be argued that accurate estimation requires the prestress level and temperature to also be taken into account). Here $f_{p}=$ ultimate strength of prestressing steel. Furthermore, $k=0.12$ for Class 1 and 0.19 for Class 2 , and for all prestressing steel including bars, $k \approx \log _{10}\left(\rho_{1,000} / \rho_{100}\right)$, where $\rho_{100}$ and $\rho_{1,000}=$ values of relaxation ratio $\rho=\left[\sigma_{0}-\sigma(t)\right] / \sigma_{0}$ measured at 100 and $1,000 \mathrm{~h}$ of relaxation, respectively. The CEB (1990) relaxation formula [Eq. (1)] is plotted in Fig. 1(a) in a semilogarithmic plot of $\sigma$ versus $\log t$.

\section{Empirical Formula Used in American Practice}

The manufacturers' data on prestress loss $\sigma_{0}-\sigma$ due to relaxation at constant strain $\varepsilon$ and constant temperature are in American practice
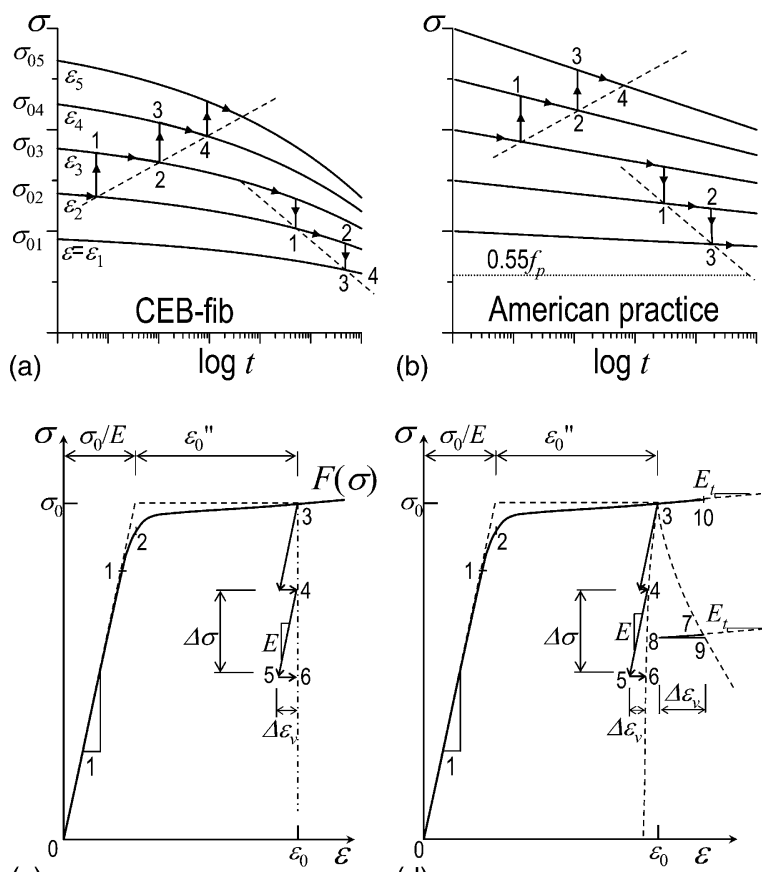

(c)

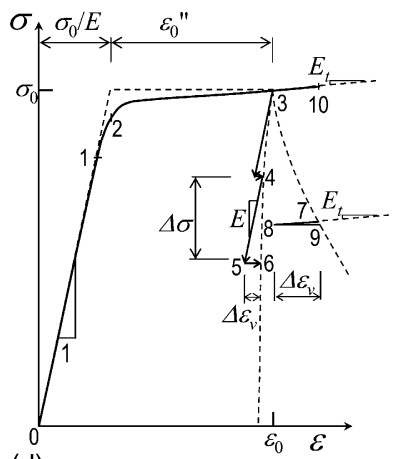

(d)

Fig. 1. (a, b) Stress relaxation at various constant levels of strain according to formula of CEB-fib and the formula from American practice, with decomposition of stress increment for relaxation during time interval $\mathrm{d} t$ at variable strain $\varepsilon(t)$; (c, d) stress-strain paths of prestressing steel during initial jacking $(\overline{0123})$ and afterward during stress relaxation $(\overline{346})$, for relaxation at constant strain $\varepsilon=\varepsilon_{0}$ in steel, and at increasing strain $\varepsilon(t)$ in steel (in which each incremental stress drop $\mathrm{d} \sigma$ during relaxation, i.e., $\overline{46}$, consists of elastic strain decrement $\overline{45}$ followed by viscoplastic strain increment $\overline{56}$ )

often approximated by the following formula, which, in the ACI notation, reads (Magura et al. 1964; see also Section 3.3 in Nawy 2006)

$$
\frac{f_{p i}-f_{p}}{\sigma_{0}}=\frac{\left\langle\ln \left(t / \lambda_{0}\right)\right\rangle}{s_{y}}\left\langle f_{p i}-s_{0}\right\rangle \quad \text { for } \varepsilon=\mathrm{constant}
$$

where $s_{0}=0.55 f_{p y}, s_{y}=(10 \ln 10) f_{p y}=23.03 f_{p y}, \lambda_{0}=1 \mathrm{~h}$ and \langle\rangle$=$ Macauley brackets, defined as $\langle x\rangle=\max (x, 0)$. This formula generally gives a slower evolution of prestress loss than the fib formula (2010) and is meaningful only for $t \gg \lambda_{0}$. But this formula is more realistic in that it has a bound that is set at $0.55 f_{b y}$. Based on the ACI notation, $\sigma=f_{p}, \sigma_{0}=\sigma(0)=f_{p i}$, and $f_{y}=f_{p y}=$ specified yield strength of prestressing steel. The typical values of $f_{y}$ are $0.80 f_{p u}$ for prestressing bars, $0.85 f_{p u}$ for stress-relieved tendons, and $0.90 f_{p u}$ for low-relaxation tendons, where $f_{p u}=$ specified tensile strength of prestressing steel. Normally, the decadic logarithm $\log _{10}$ is used in the foregoing equation, but the natural logarithm $\ln t$ is more convenient for taking the derivative.

If plotted in the semilogarithmic scale of $\sigma$ versus $\log t$, the ACI empirical formula [Eq. (2)] is a straight line [see Fig. 1(b)]. Therefore, it cannot capture the short-time relaxation accurately, although its long-time estimate is acceptable for constant strain and temperature. For different initial values of prestress $\sigma_{0}$, the plot is a system of lines with a downward slope $\sigma_{0}\left\langle\sigma_{0}-s_{0}\right\rangle / s_{y}$.

\section{Viscoplasticity of Metals}

From the mechanics viewpoint, the problem now is to find a uniaxial constitutive law for the prestressing steel that gives Eq. (1) as a solution 
for the case of $\varepsilon=$ constant. Generally, the solution is nonunique. Many different nonlinear constitutive laws can give the same stressrelaxation history [and many the same creep history, as shown in Bažant et al. (1994)]. Therefore, some further facts and hypotheses must be introduced.

First, we observe that the stress relaxation in steel is a manifestation of viscoplasticity, a phenomenon systematically studied and well understood for metals and alloys at high temperatures (Jirásek and Bažant 2002). The viscoplastic strain is independent of the stress or strain history (i.e., there is no memory). Thus the constitutive equation must be a first-order differential equation. Its simplest form, with no internal friction, is the Bingham model (Jirásek and Bažant 2002)

$$
\begin{gathered}
\dot{\varepsilon}=\dot{\varepsilon}_{i}+\dot{\varepsilon}_{v}+\alpha \dot{T} \\
\dot{\varepsilon}_{v}=f(\epsilon, \sigma) \\
\dot{\varepsilon}_{i}=\dot{\sigma} / E_{t}
\end{gathered}
$$

where

$$
E_{t}= \begin{cases}F^{\prime}(\varepsilon) & \text { if } \dot{\varepsilon}>0 \text { and } \varepsilon \geq \varepsilon_{m} \\ E & \text { otherwise }\end{cases}
$$

$\varepsilon_{m}=$ maximum strain that the steel has experienced up to the present time $t, \varepsilon=$ total normal (axial) strain in steel bar or wire, $\dot{\varepsilon}_{v}=$ viscoplastic strain, $\dot{\varepsilon}_{i}=$ instantaneous (short-time) strain, $f(\varepsilon, \sigma)=$ function to be calibrated by tests, $T=$ temperature, $\alpha=$ thermal expansion coefficient, $E_{t}=$ tangential (incremental) modulus, $E=$ initial Young's elastic modulus of prestressing steel, which also represents the unloading modulus at any strain level and the reloading modulus if $\varepsilon<\varepsilon_{m}$ [typically $E=200 \mathrm{GPa}\left(29 \times 10^{6} \mathrm{lb} / \mathrm{sq}\right.$ in. $)$ ], the superior dots represent the time derivatives, i.e., $\dot{x}=\mathrm{d} x / \mathrm{d} t$, and "otherwise" means either $\dot{\varepsilon} \leq 0$ or $\varepsilon<\varepsilon_{m}$ (unloading or reloading). If $\dot{\varepsilon}>0$, then $E_{t}=F^{\prime}(\varepsilon)=\mathrm{d} F(\varepsilon) / \mathrm{d} \varepsilon=$ plastic hardening modulus corresponding to strain $\varepsilon$. For wires, the initial prestressing normally does not exceed the linear elastic range, and then $E_{t}=F^{\prime}(\varepsilon)=E$ (but for alloy bars, this might not be the case), and $F(\varepsilon)$ is a monotonically increasing function describing the short-time uniaxial elastoplastic behavior of the prestressing steel (curve $\overline{0123}$ in Fig. 1(c and d).

The initial stress $\sigma_{0}$ enforced at the outset by the prestressing operation is

$$
\sigma_{0}=F\left(\varepsilon_{0}\right) \quad \text { at } t=0
$$

The initial portion of the curve of $F\left(\varepsilon_{0}\right)$ is straight [Fig. 1(c and d)] and describes the elastic behavior with elastic modulus $E$, i.e., $\mathrm{d} F\left(\varepsilon_{0}\right) / \mathrm{d} \varepsilon_{0}=E$. Normally $\varepsilon_{0}^{\prime \prime}=0$, but in some cases the prestress may introduce a stress $\sigma_{0}$ that is higher than the elastic limit, and then the initial inelastic strain $\varepsilon_{0}^{\prime \prime}$ is nonzero [as shown in Fig. 1(c and d)].

\section{Fédération Internationale de Béton Relaxation Formula Generalized to Variable Strain}

A constitutive law for variable strain cannot contain time $t$ explicitly. To eliminate $t$ from Eq. (1), we may first differentiate it

$$
\dot{\sigma} / F\left(\varepsilon_{0}\right)=-\rho_{1} \lambda^{-k} k t^{k-1}
$$

where we have replaced $\sigma_{0}$ with $F\left(\varepsilon_{0}\right)$. Then we express $t$ from Eq. (1) and substitute it here. This yields the following differential equation for stress relaxation at constant strain $\varepsilon=\varepsilon_{0}$ :

$$
\mathrm{d} \sigma=-\frac{\rho_{1} k}{\lambda_{1}} F\left(\epsilon_{0}\right)\left[\frac{\rho_{1}}{1-\sigma / F\left(\varepsilon_{0}\right)}\right]^{1 / k-1} \mathrm{~d} t
$$

It may be checked that integration of this differential equation at constant $\varepsilon$ for initial condition $\varepsilon=\varepsilon_{0}$ delivers Eq. (1).

Eq. (9) contains $\varepsilon_{0}$, the initial value of a variable, which is inadmissible for a constitutive relation. To get rid of it, we need to introduce the following hypothesis, which appears to be quite plausible from the viewpoint of viscoplasticity.

\section{Hypothesis I}

For variable strain history, the stress-relaxation increment $\mathrm{d} \sigma$ occurring at strain $\varepsilon$ during time interval $\mathrm{d} t[\overline{12}$ in Figs. $1(\mathrm{a}$ and $\mathrm{b})$ and $\overline{56}$ in Figs. 1(c and d )] may be calculated as if the current strain were maintained constant from the beginning. In other words, the infinitesimal stress-relaxation increments are independent of the previous history and depend only on the current strain and stress, which is a defining characteristic of viscoplasticity; see function $f(\varepsilon, \sigma)$ in Eq. (3).

Graphically, this hypothesis means that a small increment $(\Delta \varepsilon, \Delta \sigma)[\overline{13}$ in Figs. 1(a and b)] may be decomposed into stressrelaxation increment $\Delta \sigma$ [ $\overline{12}$ in Figs. 1(a and b), imagined to occur at constant $\varepsilon$ ], followed by an instantaneous jump up or down $[\overline{23}$ in Figs. 1(a and b)], from the relaxation curve for constant $\varepsilon[\overline{12}$ in Figs. 1 (a and b)] to the relaxation curve for constant $(\varepsilon+\Delta \varepsilon)[\overline{34}$ in Figs. 1(a and b)].

According to the hypothesis made, the total stress increment $\mathrm{d} \sigma=E_{t} \mathrm{~d} \varepsilon$ must be added to the stress-relaxation increment in Eq. (9) when the strain increment $\mathrm{d} \varepsilon$ is nonzero. Thus, after some rearrangements, Eq. (9) becomes

$$
\dot{\varepsilon}=\dot{\varepsilon}_{i}+\dot{\varepsilon}_{v}, \quad \dot{\varepsilon}=\frac{\dot{\sigma}}{E_{t}}+\frac{k \rho_{1}^{1 / k}}{E_{t} \lambda_{1}} \frac{F(\varepsilon)}{[1-\sigma / F(\varepsilon)]^{1 / k-1}}
$$

This is the general constitutive equation that we have been seeking. Note here that the parameter $\rho_{1}$ is a function of strain $\varepsilon$ (as well as temperature). It may be checked that integration of this differential equation for the special case $\dot{\varepsilon}=0$ with the initial condition $\varepsilon=\varepsilon_{0}$ leads to Eq. (1).

The constitutive equation also can be written in the form corresponding to a nonlinear Kelvin rheologic model

$$
\dot{\varepsilon}=\frac{\dot{\sigma}}{E_{t}}+\frac{\sigma}{\eta}
$$

in which $\eta$ is a viscosity depending on both the current stress and strain and is expressed as

$$
\eta=\frac{E_{t} \lambda_{1}}{k \rho_{1}^{1 / k}} \frac{\sigma}{F(\varepsilon)}\left[1-\frac{\sigma}{F(\varepsilon)}\right]^{1 / k-1}
$$

\section{American Practice Formula Generalized to Variable Strain}

Again we differentiate the relaxation Eq. (2) with respect to time $t$ and then substitute the expression for $t$ obtained by solving Eq. (2). This furnishes 


$$
\dot{\sigma}=\frac{\sigma_{0}\left\langle\sigma_{0}-s_{0}\right\rangle}{s_{y} \lambda_{0}} \exp \left(-\frac{s_{y}}{\left\langle\sigma_{0}-s_{0}\right\rangle}\left\langle 1-\frac{\sigma}{\sigma_{0}}\right\rangle\right)
$$

for $\varepsilon=$ constant

Using Hypothesis I, we then generalize this equation to the following constitutive equation at variable strain (valid only if $\left.t \gg \lambda_{0}\right)$ :

$$
\begin{aligned}
\dot{\varepsilon} & =\frac{\dot{\sigma}}{E_{t}}+\dot{\varepsilon}_{v}, \\
\dot{\varepsilon}_{v} & =\frac{F(\varepsilon)}{E_{t} s_{y} \lambda_{0}}\left\langle F(\varepsilon)-s_{0}\right\rangle \exp \left[-\frac{s_{y}}{\left\langle F(\varepsilon)-s_{0}\right\rangle}\left\langle 1-\frac{\sigma}{F(\varepsilon)}\right\rangle\right]
\end{aligned}
$$

\section{Implementation in Step-by-Step FEM Creep Analysis of Structures}

When the strain in concrete to which the steel is bonded varies appreciably due to concrete creep (as in the KB Bridge in Palau) (see Bažant et al. 2010, 2012b), Eq. (10) requires imposing in each time step $\Delta t$ of structural creep analysis the following inelastic strain increments in the finite elements (bar elements) of the prestressing tendons

$$
\Delta \varepsilon_{v}=\frac{\sigma}{\eta} \Delta t=\frac{k \rho_{1}^{1 / k}}{E_{t} \lambda_{1}} \frac{F(\varepsilon)}{[1-\sigma / F(\varepsilon)]^{1 / k-1}} \Delta t
$$

Normally, $E_{t}=E$, but should the strain exceed the elastic limit for the initial elastic loading (which may happen for alloy bars under high prestress), the tangential modulus $E_{t}<E$ for loading.

If no iterations of the time step $\Delta t$ are used, this expression must be used in the sense of a forward finite difference in time, in which $\sigma$ and $\varepsilon$ are taken with the values at the end of the preceding time step. It is, of course, more accurate to iterate the time step, in which case this expression is used in the second iteration in the sense of a centraldifference approximation, with $\sigma$ and $\varepsilon$ representing the average of the starting and ending values obtained in the first iteration.

A similar expression for $\Delta \varepsilon_{v}$ may be written for the constitutive Eq. (14) corresponding to the American practice

$$
\begin{aligned}
\Delta \varepsilon_{v} & =\frac{\sigma}{\eta} \Delta t \\
& =\frac{F(\varepsilon)}{E_{t} s_{y} \lambda_{0}}\left\langle F(\varepsilon)-s_{0}\right\rangle \exp \left[-\frac{s_{y}}{\left\langle F(\varepsilon)-s_{0}\right\rangle}\left\langle 1-\frac{\sigma}{F(\varepsilon)}\right\rangle\right] \Delta t
\end{aligned}
$$

A detailed algorithm for creep structural analysis incorporating the present model for steel relaxation is presented in $\mathrm{Yu}$, Bažant and Wendner (2012).

\section{Comparisons with Relaxation Tests}

During 1940-1990, numerous steel relaxation tests were carried out (see Dawance 1948; Magnel 1948; Spare 1952, 1954; Bannister 1953; Clark and Walley 1953; Gifford 1953; deStrycher 1953; Schwier 1955; Dumas 1958; Kajfasz 1958; Levi 1958; Papsdorf and Schwier 1958; Jevtic 1959; Kingham et al. 1961; Magura et al. 1964; Glodowski and Lorenzetti 1972; and Buckler and Scribner 1985). Among these tests, those of Magura et al. (1964) at constant strain were most extensive, and those conducted by Buckler and Scribner
(1985) were the only significant tests that included variable strain [Glodowski and Lorenzetti (1972) also reported a test at variable strain, but only one]. Buckler and Scribner's (1985) tests were conducted on stress-relieved strands of ultimate strength $f_{p u}=$ $2,000 \mathrm{MPa}(289.9 \mathrm{ksi})$, yield strength $f_{y}$ (defined by $1 \%$ offset $)=$ $1,807 \mathrm{MPa}(262 \mathrm{ksi})$, and elastic modulus $E=194.5 \mathrm{GPa}(28,200$ $\mathrm{ksi}$ ). In Test I, the stress-relieved strands were fixed at both ends after being prestressed to different stress levels, and then the relaxation was measured up to about $1,000 \mathrm{~h}$. In Test II, a sudden strain (and stress) drop in the prestressed strands was introduced by loosening the anchor after $24 \mathrm{~h}$ of relaxation. Then the anchor was tightened again at its new position, and further relaxation was measured up to about $1,000 \mathrm{~h}$.

The differential Eq. (15) for the fib (2010) model and Eq. (16) for American practice are integrated, and the results are shown in Fig. 2 as the solid and dashed curves, respectively (for a piecewise constant strain history, analytical integration is possible, although numerical integration was more convenient). The curves integrated for different initial prestress levels are compared in the figure with the test results of Buckler and Scribner (1985), represented by the circled points in Fig. 2.

As seen in Fig. 2, Eq. (16), popular in American practice, does not fit the Test I measurements well. This is not surprising because Eq. (2) is intended to predict the relaxation for long durations only. But describing solely the long durations is acceptable only if the creep of concrete is not significantly affected by errors in the stress of prestressing steel, which is frequently not true (as in the case of the KB Bridge or dozens of other excessively deflecting bridges) (see Bažant et al. 2012a, b).

Eq. (15) of the fib (2010) model, on the other hand, gives a close fit of the test data for relaxation at various constant strain values. For all the fits in Fig. 2, $k=0.25$, which is obtained as the mean of optimal values from a separate regression for each different $\sigma_{0}$. To determine optimal parameter $\rho_{1}$, the data for $\sigma_{0}=1,117,1,214$, $1,303,1,400$, and 1,490 $\mathrm{MPa}(162,176,189,203$, and $216 \mathrm{ksi})$ are first fitted individually, and the corresponding optimal $\rho_{1}$ values are found to be $0.024,0.029,0.052,0.058$, and 0.080 . Because the initial value $\sigma_{0}$ cannot occur in a constitutive law, parameter $\rho_{1}$ must be considered to be a function of $\varepsilon$, as shown by the data points in

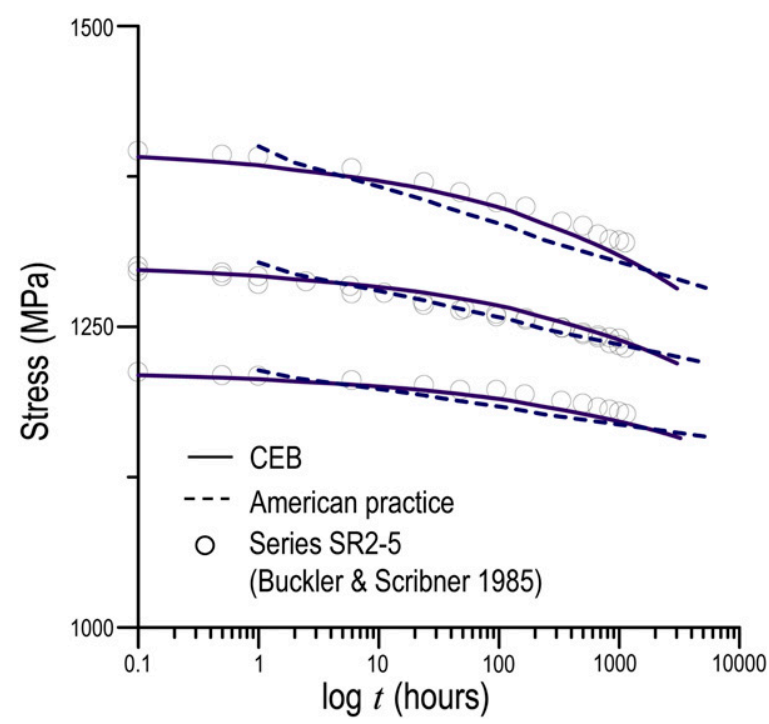

Fig. 2. Simulation results based on CEB-fib (solid curve) and American practice (dashed curve) compared with the tests data (Buckler and Scribner 1985) 
Fig. 3(a). These data can be satisfactorily fitted by a straight line, which gives

$$
\rho_{1}=0.15\left[\frac{F(\varepsilon)}{0.55 f_{y}}-1\right]
$$

(for $\rho_{1}>0$ ). Fig. 3(a) documents that this equation gives a good agreement. For the stress-relieved strands used in Tests I and II, the elastic limit is about $1,724 \mathrm{MPa}(250 \mathrm{ksi})$. This is higher than the highest initial prestress $\sigma_{0}$ of 1,490 MPa (216 ksi) [see Fig. 3(b)], and so one can replace $F(\varepsilon)$ in Eq. (17) with $E \varepsilon$.

After Eq. (17) is verified and calibrated by Test I, Test II with strain step is simulated. It makes no sense to consider Eq. (16) because it does not fit Test I for constant strain relaxation. Thus only Eq. (15) is considered for Test II. The results are compared in Figs. 4(a and b), respectively, to the data points measured for the initial stress $\sigma_{0}$ of $1,303 \mathrm{MPa}(189 \mathrm{ksi})$ or $1,400 \mathrm{MPa}(203 \mathrm{ksi})$ dropped at $24 \mathrm{~h}$ to $1,214 \mathrm{MPa}$ (176 ksi) or 1,214 MPa (176 ksi). The agreement is seen to be quite good.

\section{Improved Constitutive Law for Prestressing Steel Relaxation}

For the rate-type generalization Eq. (15) of the current fib (2010) formula, Eq. (1) seems to give good enough results. But this positive observation is due to a limited data range. Besides, there are two other problems:

1. Contrary to Eq. (1), the relaxation in steel stops if the stress drops to $\gamma f_{y}^{\prime}$ [where typically $\gamma=0.55$ (Kajfasz 1958; Magura et al. 1964), although the precise value of threshold $\gamma$ varies slightly with the type of steel; probably $\gamma \geq 0.45$ might be a realistic bound].

2. Another problem of Eq. (1) is that for the same steel, the relaxation curves for different constant strains will cross each other after a long enough time. To check this, we differentiate Eq. (1) with respect to $\sigma_{0}$ at constant $t$

$$
\frac{\mathrm{d} \sigma}{\mathrm{d} \sigma_{0}}=1-\left(\rho_{1}+\sigma_{0} \rho_{1}^{\prime}\right)\left(\frac{t}{\lambda_{1}}\right)^{k}
$$

Here $\mathrm{d} \rho_{1} / \mathrm{d} \sigma_{0}>0$, which guarantees that the relaxation curves will cross at sufficiently large $t$ (although it usually occurs beyond the conceivable lifetime).
To remedy the aforementioned problems, an improved relaxation formula for constant strain is proposed

$$
\sigma=\min \left(\gamma f_{y}^{\prime}, \sigma_{0}\right)+f_{y}^{\prime}\left\langle\frac{\sigma_{0}}{f_{y}{ }^{\prime}}-\gamma\right\rangle\left[1+\frac{\rho}{c}\left(\frac{t}{\lambda}\right)^{k}\right]^{-c}
$$

This equation satisfies the following four conditions:

1. For $\sigma_{0} \leq \gamma f_{y}^{\prime}$, there must be no relaxation.

2. The relaxing stress must approach $\gamma f_{y}^{\prime}$ for $t \rightarrow \infty$.

3. For short times $t$, Eq. (19) must asymptotically approach the fib (2010) formula [Eq. (1)].

4. The relaxation curves for different constants $\varepsilon$ must never cross each other, which requires that $c(1-\gamma) h \leq 1$, where $h=$ material constant.

For variable strain $\varepsilon(t)$, the same procedure as before leads from Eq. (19) to the following improved constitutive relation for arbitrary strain variation:

$$
\begin{aligned}
& \dot{\varepsilon}=\dot{\varepsilon}_{i}+\dot{\varepsilon}_{v}, \\
& \dot{\varepsilon}=\frac{\dot{\sigma}}{E_{t}}+\frac{\left\langle F(\varepsilon)-\gamma f_{y}^{\prime}\right\rangle}{E_{t}} \frac{k \rho^{1 / k} c^{1-1 / k}}{\lambda \zeta^{1+1 / c}}\left(\zeta^{1 / c}-1\right)^{1-1 / k}
\end{aligned}
$$

where

$$
\zeta=\frac{F(\varepsilon)-\gamma f_{y}^{\prime}}{\sigma-\gamma f_{y}^{\prime}}, \quad \rho=\rho_{0} e^{h \xi}
$$

$k, c, \rho_{0}, h=$ positive empirical constants for the given steel, and $\rho=$ empirical function of the current strain $\varepsilon(t)$, which can be determined by optimal fitting of the experimental data for various strain levels (and room temperatures), as shown by the linear regression of data in Fig. 5. Generally, the value of $c$ can be selected as 2 .

For the tests of straight oil-tempered wire [manufactured by Wickwire Spencer Company, OT Series of Magura et al. (1964)], the regression result is $\rho_{0}=0.34$ and $h=0.01$. But subsequent steel relaxation studies (Magura et al. 1964; Buckler and Scribner 1985; Rostásy and Thienel 1991) show that the value of $h$ is very small and that setting $h=0$ makes a negligible difference. Therefore, in what follows, $h=0$ is used. This not only simplifies the proposed relaxation formula but also ensures that the relaxation curves for different $\sigma_{0}$ never cross. At constant strain, $F(\varepsilon)=\sigma_{0}=$ initial prestress. Note that at variable temperature, the thermal-strain increment $\alpha \Delta T$ must be taken into account according to Eq. (3).
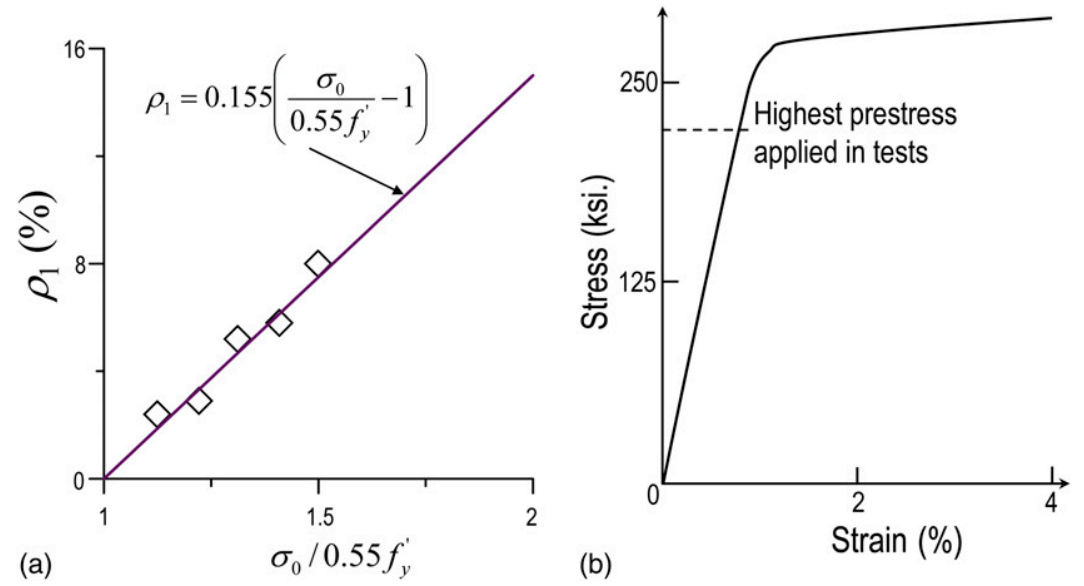

Fig. 3. (a) Best fit of $\rho_{1}-\varepsilon_{0}$ curve; (b) stress-strain curve of the strand used in tests (Buckler and Scribner 1985) 

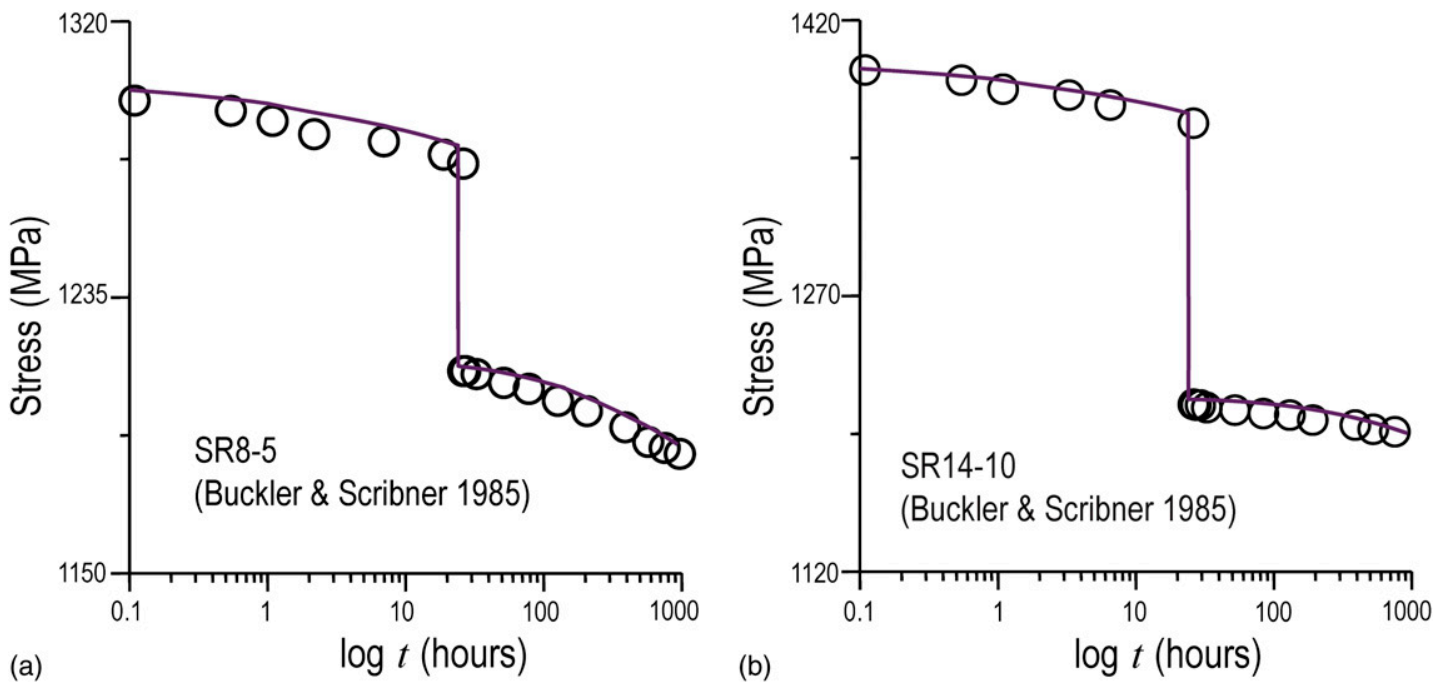

Fig. 4. Simulations based on Eq. (15) are compared with tests (Buckler and Scribner 1985) for (a) $5 \%$ load drop and (b) $10 \%$ load drop after $24 \mathrm{~h}$

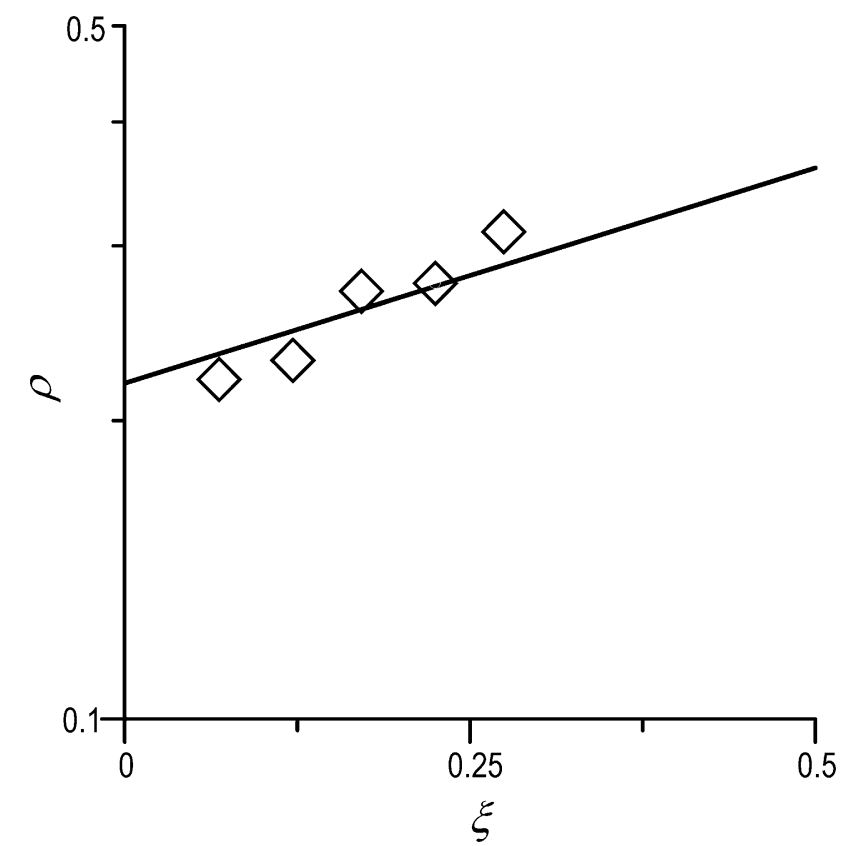

Fig. 5. Regression to obtain $\rho$ based on Eq. (21)

Eq. (19) for constant strain and Eq. (20) for varying strain describe the test data quite well. Fig. 6 shows a comparison of the computer integration of Eq. (19) or Eq. (20) for constant strain with the tests of (1) steel wire (Magura et al. 1964). (2) straight oil-tempered wire (Magura et al. 1964), and (3) stress-relieved strand (Buckler and Scribner 1985). Furthermore, Fig. 7 shows a comparison of the computer integration of Eq. (20) for strain histories with one sudden stress drop in magnitude of about $5 \%$ or $10 \%$, both imposed at $t=24 \mathrm{~h}$ (Buckler and Scribner 1985). It can be seen that the new proposed formula agrees with all these experimental results very well.

\section{Effect of Temperature}

An increase in temperature strongly accelerates the flow of metals and thus also the prestressing steel relaxation. The acceleration may be characterized by considering time $t$ in all the preceding equations as the effective (or reduced) time, defined as

$$
\mathrm{d} t=A_{T} \mathrm{~d} \tau \quad \text { or } \quad t=\int_{\tau^{\prime}=0}^{\tau} A_{T}\left(\tau^{\prime}\right) \mathrm{d} \tau^{\prime}
$$

where

$$
A_{T}(t)=\exp \left[\frac{Q}{k_{B} T_{0}}-\frac{Q}{k_{B} T(t)}\right]
$$

$\tau=$ real time, $T(t)=$ absolute temperature at time $t, A_{T}=$ Arrhenius factor (Cottrell 1964), chosen so that $A_{T}=1$ at $T_{0}, T_{0}=298 \mathrm{~K}=$ reference (room) temperature, $Q=$ activation energy of flow of prestressing steel, and $k_{B}=$ Boltzmann's constant $\left(k_{B}=1.381 \times\right.$ $10^{-23} \mathrm{~J} / \mathrm{K}$ ). In Eqs. (15) and (16), $\Delta t=A_{T} \Delta \tau$. Eqs. (1), (2), and (19) for constant strain remain valid for any constant temperature $T \neq T_{0}$ if $t=A_{T} \tau$ is substituted.

To calibrate the temperature effect, data from the Shinko Wire Co., Ltd. (Japan), have been used; see Fig. 8. The times to reach the loss of $4 \%$ for normal relaxation-grade steel have been extracted from the figure and are shown by the circled points in Fig. 8(b) as the plot of $\ln (t / \tau)$ versus $1 / T$. This plot represents linear regression, and the slope of the regression line gives $Q / k_{B} \approx 14,600 \mathrm{~K}$. Strictly speaking, the value of $f_{y}^{\prime}$ and the nonlinear portion of function $F(\varepsilon)$ are also affected by temperature, but these effects are negligible for the temperatures caused by sun illumination (they are important for fire exposure) (Bažant et al. 2008).

Using the constants obtained by fitting relaxation at $20^{\circ} \mathrm{C}$ by Eq. (19), one is able to predict the relaxations for different temperatures. As evidenced by Fig. 9, the new proposed Eq. (19) agrees very well with the data recorded by Shinko. In comparison with the curve for $20^{\circ} \mathrm{C}$, the figure demonstrates that elevated temperatures due to sun exposure in hot countries can enormously accelerate the stress relaxation. For example, according to Eq. (19) for constant strain, it takes 100 years for the initial prestress to drop by $13 \%$ due to relaxation alone at $20^{\circ} \mathrm{C}$, but at $40^{\circ} \mathrm{C}$ the same prestress loss occurs within 4 years. This time is, in practice, of course, roughly doubled because the temperature fluctuates daily 
(a)

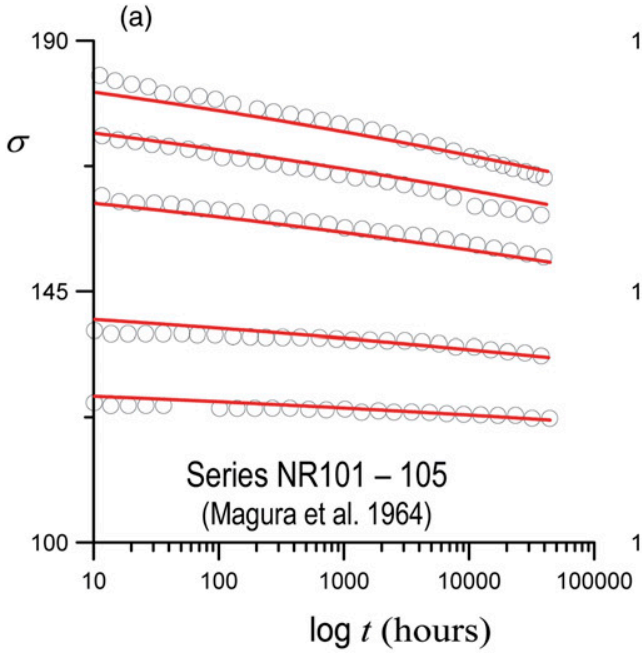

(b)

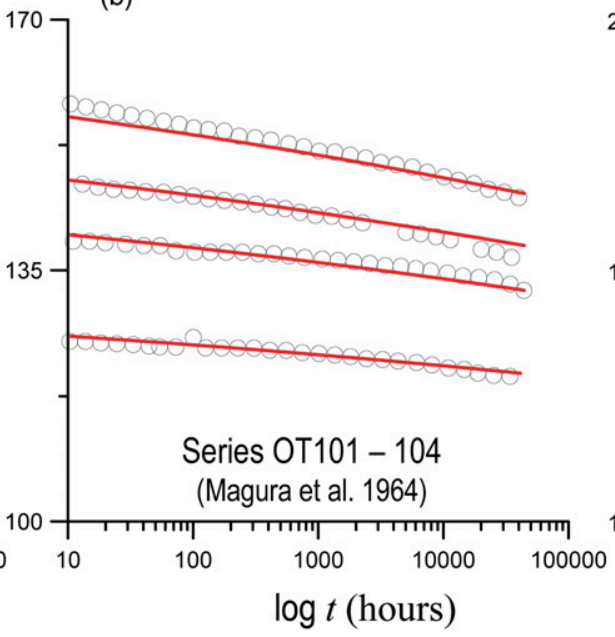

(c)

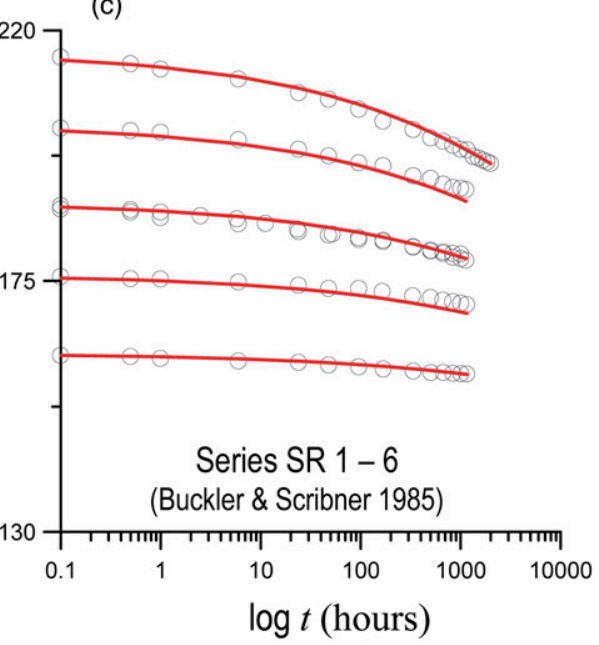

Fig. 6. Simulations based on Eq. (20) are compared with tests under constant strain (Buckler and Scribner 1985; Magura et al. 1964)
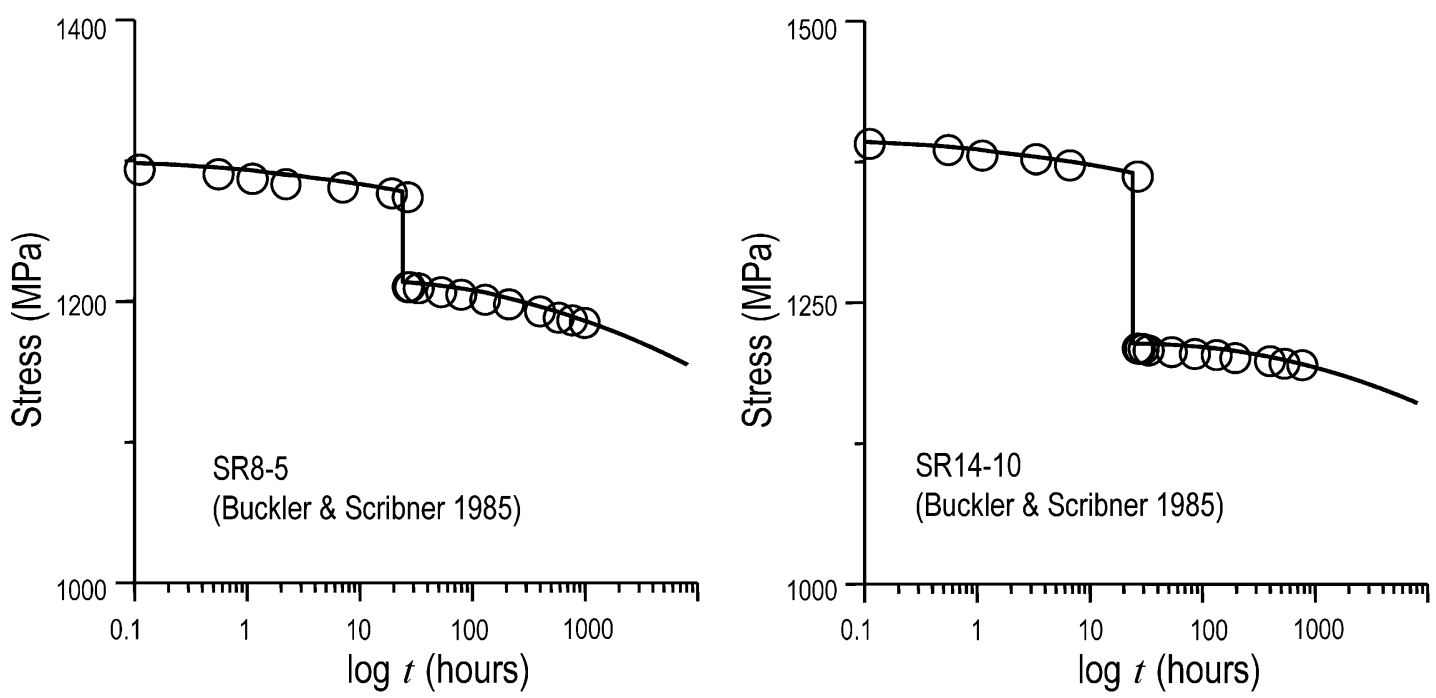

Fig. 7. Simulations based on Eq. (20) are compared with tests under varied strain (Buckler and Scribner 1985)
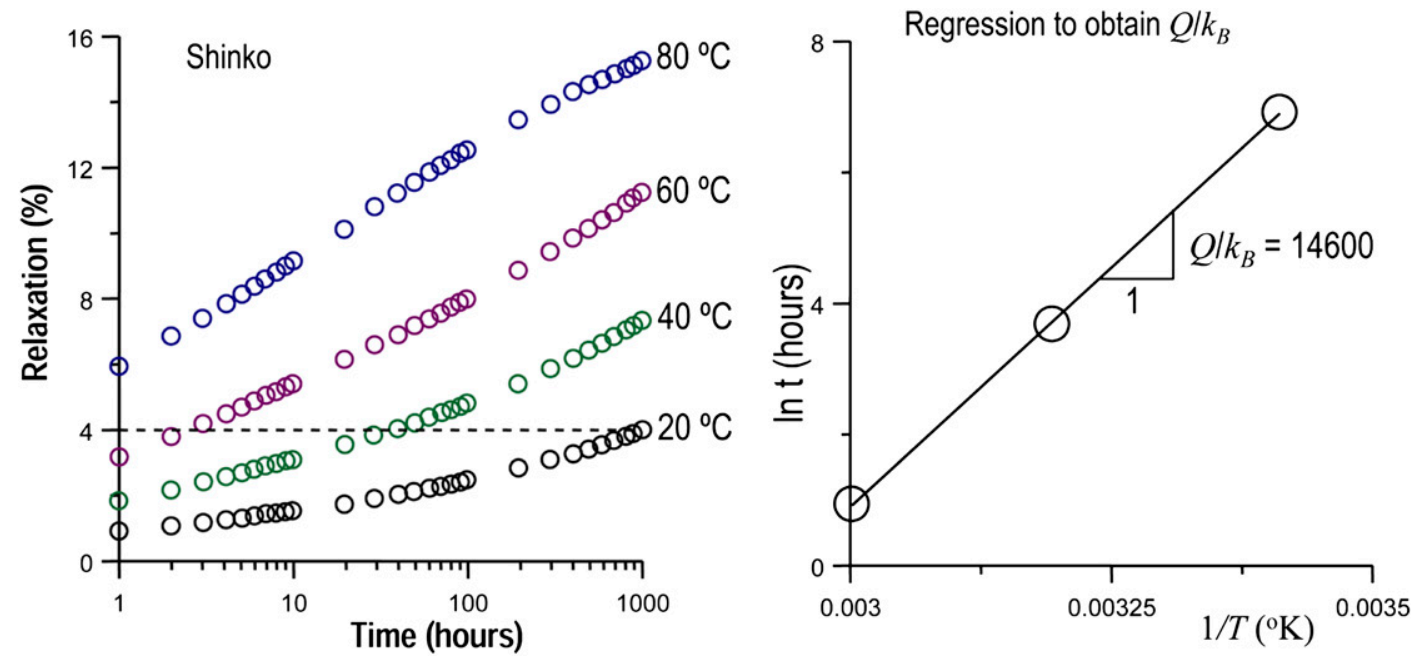

Fig. 8. Relaxation at different temperatures measured by Shinko and the regression plot giving the material constant $Q / k$ based on the times to reach a $4 \%$ stress-relaxation drop 
between 40 and $20^{\circ} \mathrm{C}$. Integration of $t$ from Eq. (22) gives the same degree of relaxation within about 8 years.

This observation reveals that at locations where the sunshine can heat the pavement substantially, the tendons in the top slab should be placed as deep below the top surface as possible, and the pavement should have the lowest possible thermal conductivity or contain an insulating layer. The acceleration of prestress loss by elevated temperature means that the threshold $\gamma f_{y}^{\prime}$ can be approached closely within real lifetimes and that the condition of no crossing of relaxation curves can become important. Therefore, in the case of elevated temperatures, Eq. (20) must be used instead of Eq. (10).

Similarly, Eqs. (19) and (22) are compared with the tests conducted by Rostásy and Thienel (1991). Unlike the data from Shinko, the highest temperature used in their tests reached $175^{\circ} \mathrm{C}$, and so the effect of temperature on the yield strength must be considered in the fitting of these data. In Fig. 9 it can be seen that the prediction agrees with the test data very well for temperatures from 20 to $175^{\circ} \mathrm{C}$.

Furthermore, the relaxation formulas proposed here are also compared with the relaxation tests under stepwise heating. The temperature history used in Rostásy and Thienel's (1991) tests is reproduced in Fig. 10. In these tests, the thermal expansion due to temperature change is eliminated from the total strain, and the mechanically induced initial strain is kept constant. Beside the thermal expansion, it is also well known that heating will increase the inelastic strain in the steel. Here it is assumed that for heating by 1 degree, the increase in the average inelastic strain increase is $2.8 \times 10^{-6}$. Then, when compared with the tests, the predictions based on Eqs. (19) and (22) seem to be acceptable; see Fig. 10.
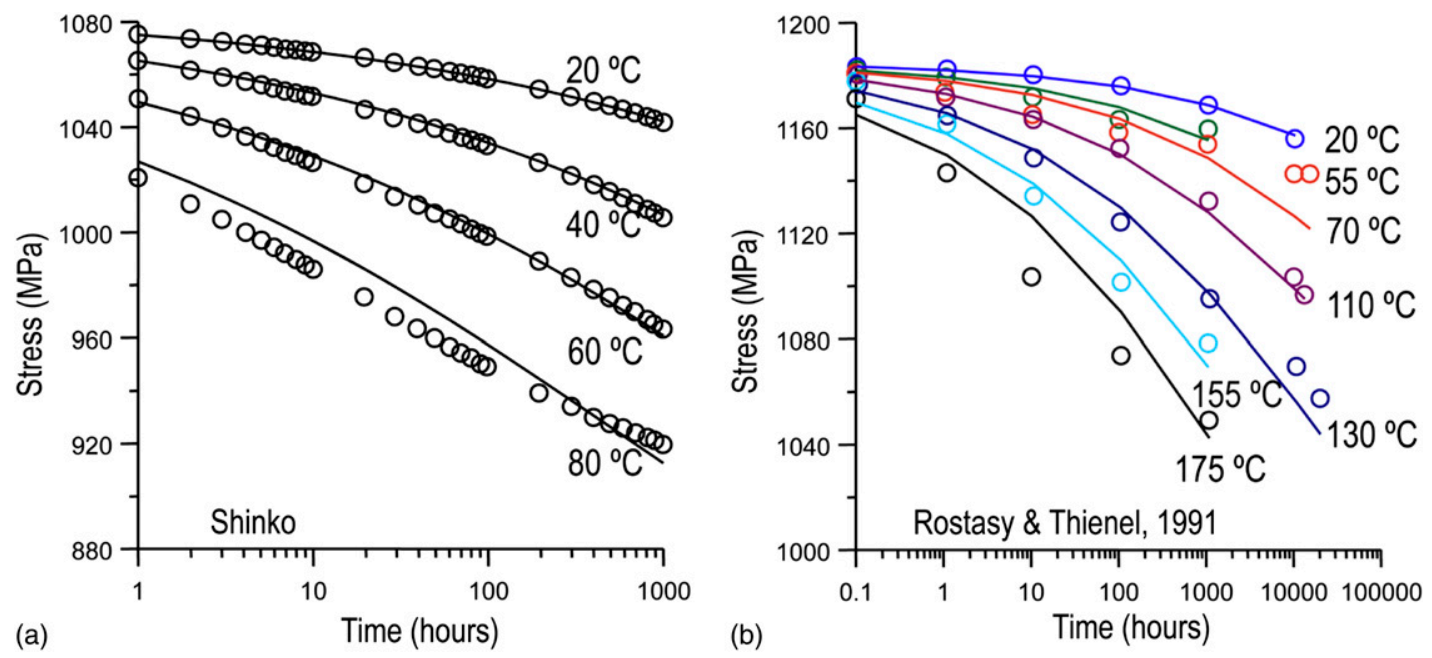

Fig. 9. Predictions based on material constants identified from tests at $20^{\circ} \mathrm{C}$ : (a) for Shinko tests; (b) for Rostasy and Thienel (1991) tests
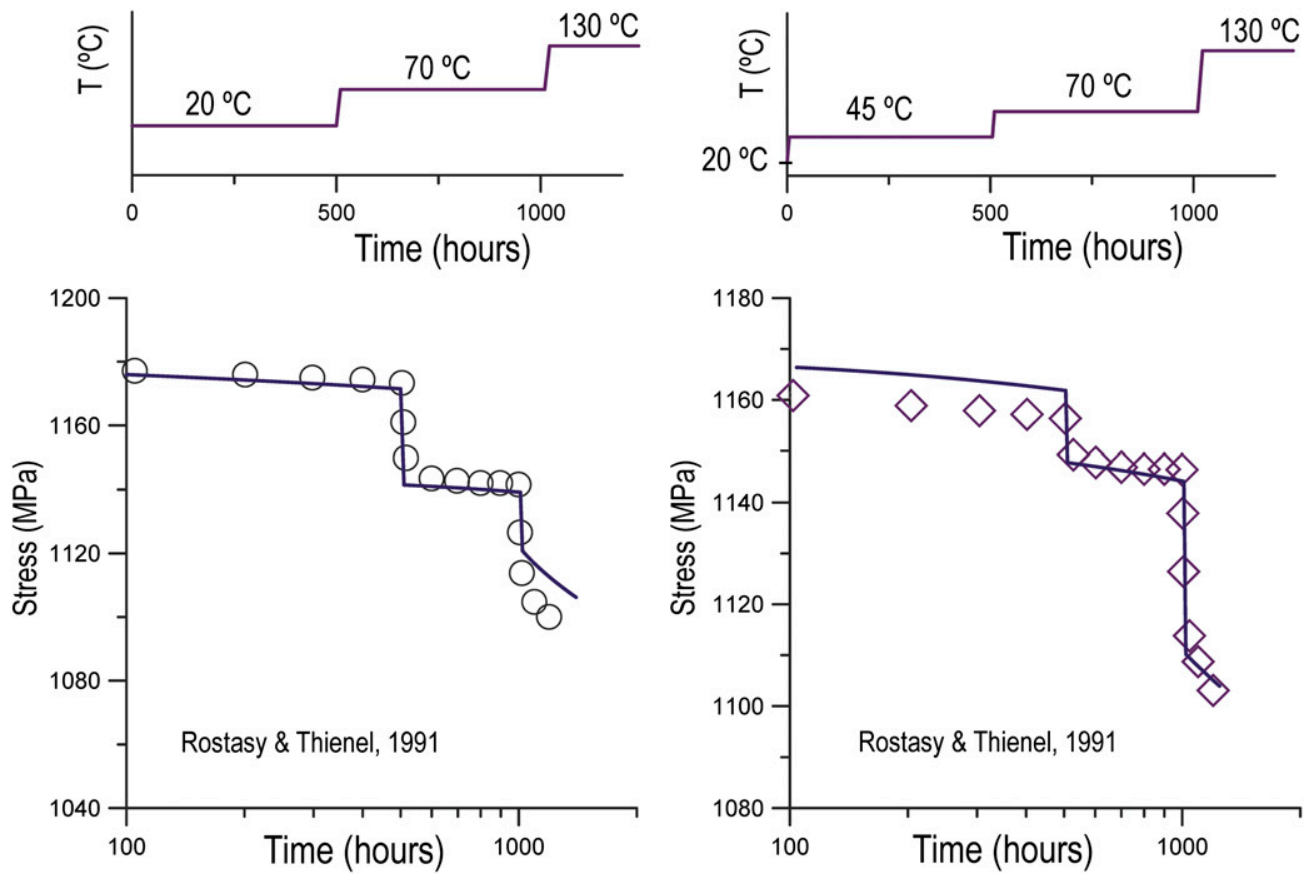

Fig. 10. Predictions of the proposed formula compared with the tests at stepwise heating 
To generalize Eq. (20) to variable temperature, the thermal expansion rate $\alpha \dot{T}$ has been added to the right-hand side and it was assumed that the accumulated strain rate should not be subtracted from total strain $\varepsilon$ in function $F \varepsilon$.

Furthermore, it was noted (M. Jirásek, personal communication, Jan. 1, 2013) that, during cooling, the calculation of $\zeta$ in Eq. (21) could in general cause $\zeta<1$. In that case, the power function of the parenthetic expression in Eq. (20) would become undefined. Therefore, in programming, $\zeta$ must not be allowed to drop below some constant close to 1 . For example, it can be replaced with $\left(\zeta^{u+1}+1.01\right) /\left(\zeta^{u}+1\right)$, where $u$ is a positive constant. This is, of course, only an ad hoc trick to prevent the program from crashing, but new test data would be needed to validate this experimentally.

\section{Main Points and Conclusions}

1. A constitutive equation for steel relaxation at variable strain and variable temperature has been developed on the basis of metal viscoplasticity and the activation-energy theory.

2. The new constitutive equation amalgamates and extends the steel relaxation formulas for constant strain and constant temperature used in the European design code and American practice.

3. The resulting steel relaxation formula is a memoryless equation for the viscoplastic strain rate of steel as a function of the current stress, strain, and temperature.

4. Satisfactory agreement has been attained with the main existing test data for prestressing steel. Calibration of the coefficients of the constitutive equation according to data for the particular prestressing steel to be used is advisable.

5. In large-span structures of high creep sensitivity dominated by self-weight, the prestress loss due to steel relaxation cannot be separated from the analysis of concrete creep and shrinkage effects in the structure. The concrete creep and shrinkage affect the steel relaxation, and the steel relaxation affects the concrete creep.

6. The rate form of the equation makes it easy to use in stepby-step FEM programs for creep analysis of concrete structures. However, linear viscoelastic creep analysis based on the principle of superposition is insufficient to determine the effects of steel relaxation at variable strain and temperature because the viscoplastic constitutive equation is nonlinear.

7. The present refinement of the steel relaxation formula is important for large concrete structures of high creep sensitivity.

8. The existing experimental evidence for the relaxation of prestressing steel at varying strain and varying temperature is quite limited. Further tests would be useful. The manufacturers should conduct their relaxation tests not only at room temperature but also at an elevated temperature such as $40^{\circ} \mathrm{C}$.

\section{Acknowledgments}

Financial support from the U.S. Department of Transportation, through Grant No. 20778 from the Infrastructure Technology Institute of Northwestern University, is gratefully acknowledged. Additional support for mathematical aspects was received from the National Science Foundation under Grant No. CMMI-1129449 to Northwestern University.

\section{References}

American Concrete Institute (ACI). (2005a). "Building code requirements for structural concrete." ACI Rep. No. 318-05, and "Commentary" ACI Rep. No. 318R-05, Farmington Hill, MI.

American Concrete Institute (ACI). (2005b). "Commentary to 'Building code requirements for structural concrete." ACI Rep. No. 318R-05, Farmington Hill, MI.

Bannister, J. L. (1953). "Cold drawn prestressing wire." The Struct. Eng., 31(8), 203-218.

Bažant, Z. P., Hubler, M. H., and Yu, Q. (2011a). "Pervasiveness of excessive segmental bridge deflections: Wake-up call for creep." $A C I$ Struct. J., 108(6), 766-774.

Bažant, Z. P., Hubler, M. H., and Yu, Q. (2011b). "Excessive creep deflections of large-span prestressed segmental box girders: An awakening." Concrete Int., 33(8), 44-46.

Bažant, Z. P., Huet, C., and Müller, H. S. (1994). "Comment on recent analysis of concrete creep linearity and applicability of principle of superposition." Mater. Struct., 27(6), 359-361.

Bažant, Z. P., Le, J.-L., Greening, F. R., and Benson, D. B. (2008). "What did and did not cause collapse of World Trade Center twin towers in New York?" J. Eng. Mech., 134(10), 892-906.

Bažant, Z. P., Yu, Q., Hubler, M., Křístek, V., and Bittnar, Z. (2011c). "Wake-up call for creep, myth about size effect and black holes in safety: What to improve in fib model code draft." Concrete Engineering for Excellence and Efficiency (Proc., fib Symp.), Czech Concrete Society (CBS), Prague, Czech Republic, 731-746.

Bažant, Z. P., Yu, Q., and Li, G.-H. (2012a). "Excessive long-time deflections of prestressed box girders. I: Record-span bridge in Palau and other paradigms." J. Struct. Eng., 138(6), 676-686.

Bažant, Z. P., Yu, Q., and Li, G.-H. (2012b). "Excessive long-time deflections of prestressed box girders. II: Numerical analysis and lessons learned." J. Struct. Eng., 138(6), 687-696.

Bažant, Z. P., Yu, Q., Li, G.-H., Klein, G. J., and Kř́istek, V. (2010). "Excessive deflections of record-span prestressed box girder: Lessons learned from the collapse of the Koror-Babeldaob Bridge in Palau." Concrete Int., 32(6), 44-52.

Buckler, J. D., and Scribner, C. F. (1985). "Relaxation characteristics of prestressing strand." Rep. No. UILU-ENG-85-2011, Univ. of Illinois, Urbana, IL.

Clark, N. W., and Walley, F. (1953). "Creep of high-tensile steel wire." Proc., Inst. Civil Eng., Part 1, 2(2), 107-135.

Comité Euro-International du Béton (CEB). (1990). "Model code for concrete structures." Bull. Inform. Nos. 213 and 214, Lausanne, Switzerland.

Cottrell, A. H. (1964). The mechanical properties of matter, Wiley, New York.

Dawance, G. (1948). "Une nouvelle méthode pour l'etude de la relaxation des fils d'acier." Ann. Inst. Tech. Batiment Travaux Publics, Paris, 28.

deStrycher, R. (1953). "Discussion of a paper by Clark and Walley." Proc., Inst. Civil Eng., Part 1, 2(2), 136-154.

Dumas, F. (1958). "The necessity for the use of the highest class materials in prestressed concrete construction." Proc., RILEM Symp. on Special Reinforcements for Reinforced Concrete and on Prestressing Reinforcements, Liège, Belgium.

Fédération Internationale de Béton (fib). (2010). Draft of fib model code, Lausanne, Switzerland.

Gifford, F. W. (1953). "Creep tests on prestressing steel." Magazine of Concrete Research, 5(14), 71-74.

Glodowski, R. J., and Lorenzetti, J. J. (1972). “A method for predicting prestress losses in a prestressed concrete structure." PCI J., 17(2), 17-31.

Jevtic, D. (1959). "Relaxation, creep fatigue tests and tests of behavior at high temperatures of steel wires for prestressed concrete." RILEM Bull. No. 4, RILEM, Bagneux, France, 66-75.

Jirásek, M., and Bažant, Z. P. (2002)., Chapter 27, Inelastic analysis of structures, Wiley, Chichester, U.K.

Kajfasz, S. (1958). "Some relaxation tests on prestressing wire." Magazine of Concrete Research, 10(30), 133-140. 
Kingham, R. I., Fisher, J. W., and Viest, I. M. (1961). "Creep and shrinkage of concrete in outdoor exposure and relaxation of prestressing steel." Special Rep. No. 66, American Association of State Highway Officials, Ottawa, IL, 103-131.

Levi, F. (1958). "Tests of steel for prestressed concrete." Proc., Second Congress of Federation Internatonale de la Precontrainte, Amsterdam, Netherlands, 137-155.

Magnel, G. (1948). "Creep of steel and concrete in relation to prestressed concrete." ACI Struct. J., 19(6), 485-500.

Magura, D. D., Sozen, M. A., and Siess, C. P. (1964). "A study of stress relaxation in prestressing reinforcement." PCI J., 9(2), $13-57$.

Nawy, E. G. (2006). Prestressed concrete: A fundamental Approach, 5th Ed., Pearson Prentice Hall, Upper Saddle River, NJ.
Papsdorf, W., and Schwier, F. (1958). "Creep and relaxation of steel wire, particularly at slightly elevated temperatures." Stahl un Eisen, 78(14), 937-947.

Rostásy, F. S., and Thienel, K.-Ch. (1991). "On prediction of relaxation of colddrawn prestressing wire under constant and variable elevated temperature." Nucl. Eng. Des., 130(2), 221-227.

Schwier, F. (1955). "Stress corrosion and relaxation of high-carbon steel wire for prestressed concrete." Wire and Wire Products, 30(12), 1473-1479.

Spare, G. T. (1952). "Creep and relaxation of high strength steel wires at room temperatures." Wire and Wire Products, 27(10), 1058-1061.

Spare, G. T. (1954). "Prestress wires: Stress-relaxation and stress-corrosion up to date." Wire and Wire Products, 29(12), 1421-1426.

Yu, Q., Bažant, Z. P., and Wendner, R. (2012). "Improved algorithm for efficient and realistic creep analysis of large creep-sensitive concrete structures." ACI Struct. J., 109(5), 665-675. 